Precision and accuracy of tree-ring-based death dates of mountain pines in the Swiss National Park

Journal Article

Author(s):

Bigler, Christof (D); Rigling, Andreas

Publication date:

2013-12

Permanent link:

https://doi.org/10.3929/ethz-b-000074750

Rights / license:

$\underline{\text { In Copyright - Non-Commercial Use Permitted }}$

Originally published in:

Trees 27(6), https://doi.org/10.1007/s00468-013-0917-6 


\title{
Precision and accuracy of tree-ring-based death dates of mountain pines in the Swiss National Park
}

\author{
Christof Bigler $\cdot$ Andreas Rigling
}

Received: 13 April 2013/Revised: 18 July 2013/Accepted: 26 July 2013/Published online: 14 August 2013

(c) Springer-Verlag Berlin Heidelberg 2013

\begin{abstract}
Key message Mountain pines in the Swiss National Park show evidence of partial cambial mortality, which affects the precision of tree-ring-based death dates, followed by lagged crown mortality.

Abstract The time of tree death is commonly reconstructed by dating the outermost ring of tree-ring series. However, due to the occurrence of partial cambial mortality, the date of the outermost tree ring may vary between different locations on the tree stem. Furthermore, a tree may continue to live following the formation of the most recent tree ring. In this study, we quantified precision and accuracy of tree-ring-based death dates from 229 dead mountain pines (Pinus montana) from a $28 \mathrm{~km}^{2}$ study area in the Swiss National Park. For almost two-thirds of the trees, a maximum difference of just 0-4 years between the dates of cambial mortality from three increment cores was observed, however, for a few trees the difference reached 30-65 years. Higher maximum differences between the dates of cambial mortality are expected for trees on steep slopes, for old trees or for trees that died a long time ago. For $84 \%$ of dead mountain pines, which were sampled in a permanent sample plot with 2-year remeasurement intervals, the difference between the date of observed crown
\end{abstract}

Communicated by E. Liang.

C. Bigler $(\bowtie)$

Forest Ecology, Institute of Terrestrial Ecosystems, Department of Environmental Systems Science, ETH Zurich, Universitätstr.

22, CHN G 77, Zurich 8092, Switzerland

e-mail: christof.bigler@env.ethz.ch

A. Rigling

Forest Dynamics, Swiss Federal Institute for Forest, Snow and Landscape Research WSL, Birmensdorf 8903, Switzerland mortality and the death date determined from three cores was 0-5 years. Sampling two or just one core per tree decreases the accuracy of tree-ring-based death dates. Based on the findings of our study, we recommend a prior assessment of the precision and accuracy of tree-ring-based death dates for any dendroecological study dealing with the reconstruction of tree mortality.

Keywords Crown transparency - Cambial mortality - Time of tree death - Tree mortality . Permanent sample plots · Generalized linear mixed-effects models

\section{Introduction}

Tree-ring analysis is a common and frequently used method to determine the time of tree death, which allows reconstructing tree mortality over long timeframes with annual resolution. Death dates of trees, as derived from dating the outermost ring of tree-ring series, have been applied to reconstruct mortality from disturbances or from extreme climate events (Smith et al. 2012; Villalba and Veblen 1998), to reconstruct forest stand dynamics (Stan et al. 2011; Metsaranta and Lieffers 2009), to estimate the time since tree death for snags and logs (Daniels et al. 1997; Jones and Daniels 2012), or to get estimates of tree lifespans (Rötheli et al. 2012; Bigler and Veblen 2009).

Tree-ring-based estimates of the time of tree death suffer several potential sources of error (Jones and Daniels 2012). First, the date, when the outermost tree ring was formed, is not necessarily identical across different sections of the tree stem, but may differ by several years up to decades. This pattern is known as partial cambial mortality and affects the precision, with which a tree-ring-based death 
date is determined. Partial cambial mortality is an irreversible process and has been observed in declining trees from a wide range of tree species (Cherubini et al. 2002; Amoroso and Daniels 2010; Jones and Daniels 2012). Thus, the occurrence of missing rings following the mortality of the cambium is caused by a different process when compared to the reversible process of missing rings resulting from e.g. severe drought years (Novak et al. 2011), which occur before the mortality of the cambium. Extreme forms of partial cambial mortality result in stripbark trees, i.e. some sections of the stem lack bark, which can be observed e.g. in Thuja occidentalis (Kelly et al. 1992; Larson et al. 1993) or in Pinus aristata (Schauer et al. 2001). In some previous studies on strip-bark trees, wind or rockfall has been attributed as the cause of partial cambial mortality (Schauer et al. 2001; Kelly et al. 1992). However, there is relatively little evidence, which factors affect the occurrence of partial cambial mortality in the less obvious form of whole-bark trees without any visible signs of mechanical wounding. Second, the date of the outermost tree ring does not necessarily reflect the true date of tree death. Following the cessation of radial wood production, a tree may continue to live for one or several years (Cherubini et al. 2002). The difference between the date of cambial mortality and the date of observed tree death (e.g. based on repeated assessments of crown condition) affects the accuracy of tree-ring-based death dates. However, apart from some anecdotal evidence (Cherubini et al. 2002; Mast and Veblen 1994; Pedersen and McCune 2002), there are currently very few studies that have systematically assessed accuracy of tree-ring-based death dates in permanent sample plots (Jones and Daniels 2012). Third, a further potential error may occur, if one or several of the outermost tree rings are eroded following tree death due to weathering, decay or mechanical damage.

In this study, we investigated precision and accuracy of tree-ring-based death dates from dead mountain pines (Pinus montana Miller) in the Swiss National Park. Mountain pine is a shade-intolerant, shallow-rooted tree species, which is tolerant to frost and low temperatures (Richardson 1998). In Switzerland, it is confined mainly to extreme sites in the montane and subalpine belt. Precision was determined covering a wide range of tree and site properties, accuracy was estimated from trees in a permanent sample plot with biennial assessment of crown conditions. The specific objectives were (i) to estimate the precision of tree-ring-based death dates; (ii) to quantify effects from tree- and site-specific characteristics on the precision of tree-ring-based death dates; (iii) to estimate the accuracy of tree-ring-based death dates (i.e. the difference between the death date based on crown transparency and based on tree rings); and (iv) to quantify the effect of sampling effort (i.e. sampling one, two or three cores per tree) on the accuracy of tree-ring-based death dates.

\section{Materials and methods}

\section{Description of the study area}

The study area is located in the Swiss National Park (SNP) in the Engadine, a high valley in south-eastern Switzerland. The SNP was founded in 1914 and is the largest protected area in the country comprising $170.3 \mathrm{~km}^{2}$ with elevations ranging from 1,400 to $3,173 \mathrm{~m}$ a.s.l. Eighty percent of the bedrock in the SNP consists of dolomite and limestone. Hence, rendzina soils with high permeability and low available water capacity are abundant.

The high elevations and the protective effect of the surrounding mountains result in a continental climate with low temperatures (annual mean $0.3{ }^{\circ} \mathrm{C}$, mean from June to September $8.8^{\circ} \mathrm{C}$ ) and relatively little precipitation (annual sum $912 \mathrm{~mm}$, sum from June to September $106 \mathrm{~mm}$ ). The climate data were measured from 1917 to 2008 at the climate station Buffalora (1970 m a.s.l.; coordinates $46^{\circ} 39^{\prime} \mathrm{N}, 10^{\circ} 10^{\prime} \mathrm{E}$ ).

Forests cover $28 \%$ of the SNP, whereof $73 \%$ consist of mountain pine (Pinus montana) and dwarf mountain pine (Pinus mugo) forests, and $11 \%$ of Swiss stone pine (Pinus cembra) -European larch (Larix decidua) forests (Zoller 1995). The treeline is located at ca. $2,250 \mathrm{~m}$ a.s.l. Since the 14 th century, there was intensive land and forest use in the area of the SNP including logging, lime kiln, mining, charcoal burning, and grazing by sheep and cattle. Logging within the study area was documented from 1650 to 1800 , in parts of the area also from 1850 to 1909 (Parolini 2012).

\section{Selection of study plots}

Twenty study plots were selected in the SNP within a perimeter of $28 \mathrm{~km}^{2}$, which was bounded by $46^{\circ} 41^{\prime} \mathrm{N}$, $10^{\circ} 10^{\prime} \mathrm{E}, 46^{\circ} 39^{\prime} \mathrm{N}$ and $10^{\circ} 16^{\prime} \mathrm{E}$. We selected the 20 plots with the ArcGIS software (version 9.1; ESRI, Redlands CA, USA) based on a GIS-layer of forest stands that were homogeneous with respect to tree species composition and percentage of standing dead wood. The forest stands had been previously delineated as polygons from colour infrared aerial photographs (Lotz 2006). Only stands $\geq 1$ ha were considered that contained $\geq 60 \%$ of mountain pine and $\geq 1-5 \%$ of standing dead wood. The plots were located between 1,900 and 2,100 m a.s.l., with mean slopes ranging between $20^{\circ}$ and $40^{\circ}$ and with each five plots facing north, east, south and west. Further field sampling was conducted at a permanent sample plot of the LongTerm Forest Ecosystem Research (LWF), which is 
maintained by the Swiss Federal Institute for Forest, Snow and Landscape Research WSL (Birmensdorf, Switzerland) and is part of the European level II monitoring network (Fischer et al. 2012; Lorenz 1995). The LWF plot is located at $46^{\circ} 40^{\prime} \mathrm{N} / 10^{\circ} 14^{\prime} \mathrm{E}$ on $1,900 \mathrm{~m}$ a.s.l., slope steepness is $6^{\circ}$ (Dobbertin et al. 2001). Since 1996, crown condition of every tree $\geq 12 \mathrm{~cm} \mathrm{DBH}$ (diameter at breast height) is assessed on average every 2 years. Crown transparency is visually estimated in steps of $5 \%$, with $100 \%$ crown transparency (i.e. lack of green needles) indicating tree death.

\section{Field sampling}

In 2009, dead standing mountain pines with a DBH $\geq 10 \mathrm{~cm}$ were sampled in the field. At the 20 plots, every dead standing tree was sampled until ten trees were included in the sample of each plot resulting in a total of 200 dead trees (Table 1). Trees were typically sampled within an area of ca. $30 \times 30 \mathrm{~m}$. A tree was assessed to be dead if no green needles in the crown were visible. At the LWF plot, 29 dead standing mountain pines were sampled that died since 1996 according to the repeated assessment of the crown condition (Table 1). Tree mortality of the sampled trees on the 20 plots and on the LWF plot was not related to any large-scale disturbances such as fire, blowdown, avalanches or insect outbreaks. Furthermore, most sampled trees did not reveal external signs of mechanical wounding.

From each dead tree, three increment cores were removed with an increment borer. Stem sections with obvious evidence of eroded wood were avoided. Core B was taken at the base of the stem on the downhill side (Table 1), which allowed to get close to the shoot-root interface. Cores $\mathrm{L}$ and $\mathrm{R}$ were taken parallel to the contour line from a higher tree height, with core L on the left side of the stem (viewing direction pointed downward) and core $\mathrm{R}$ on the right side (Table 1). If the targeted direction for removing a core could not be met due to branches, injuries on the stem or decayed stem sections, the core was taken from a slightly different direction. Three cores could be extracted from most trees, for a few trees only two or one core could be removed because of advanced decay of the tree stem (Table 1), and from nine trees no core could be removed. At 19 of the 20 plots, two living mountain pines were sampled per plot with one core per tree resulting in a total of 38 living trees. The tree-ring chronology derived from these cores was used to crossdate the tree-ring series of the dead trees.

From each dead tree at the 20 plots and at the LWF plot, tree-specific measurements were noted including $\mathrm{DBH}$ (measured at $130 \mathrm{~cm}$ height with a diameter tape; Table 1), tree decay (decay classes: $\mathrm{A}=$ brown needles present,
$\mathrm{B}=$ some twigs remaining but no needles, $\mathrm{C}=$ some branches left, $\mathrm{D}=$ only the bole remaining), and bark remaining on the stem (visually estimated in $10 \%$ steps). Since most living mountain pines observed in the field were whole-bark trees, we assumed that missing bark was for most dead trees not related to strip-bark growth, but was caused by the mortality of the entire cambium, when the trees died. At the 20 plots, additional measurements were taken including tree height (measured with a Vertex IV from Haglöf, Sweden), elevation (average over 50 repeated measurements from a Garmin GPS, USA) and slope steepness (measured with a Vertex; Table 1).

Processing of increment cores and tree rings

The increment cores were glued on core mounts, air dried and sanded with successively finer sanding paper from 180 to 600 grit. The tree rings of the dead and living mountain pines were measured on a LINTAB 5 measuring stage with a resolution of $0.01 \mathrm{~mm}$, which was connected to a computer with the TSAP-Win (version 4.67) software (both from RINNTECH, Heidelberg, Germany). Two dead trees from one of the 20 plots were excluded from the data set, because the cores were identified as Swiss stone pine. Two cores of dead mountain pines were in advanced stage of decay and could not be measured. For cores lacking bark, we checked under the microscope, whether the outermost tree rings were eroded.

We crossdated the tree rings visually under the microscope and with TSAP-Win and quantitatively with the COFECHA software (Holmes 1983). Crossdating is based on the synchronous match of tree-ring series from different trees caused by the year-to-year climate variability, which allows assigning the correct calendar year to each tree ring (Speer 2010). A tree-ring chronology, which covers the time span from 1681 to 2008, was developed from 32 of the 38 sampled living mountain pines and complemented with cores from 12 dead mountain pines (Fig. 1). The tree-ring series of the remaining dead mountain pines were crossdated against the chronology. Only few missing rings had to be inserted along the tree-ring series (i.e. prior to the formation of the outermost tree ring). For the following analyses, only crossdated cores without eroded outermost tree rings were used (Table 1), which yielded a reliable calendar year for the most recent tree ring defined hereafter as date of cambial mortality.

For each tree at the 20 plots with three measured and crossdated cores, we estimated the establishment date, the tree-ring-based death date, and the tree age (Table 1). The establishment date was based on the oldest pith date from the three cores. For cores, which did not hit the pith, we estimated the number of missed rings between pith and the first ring on the core (Duncan 1989). The tree-ring-based 
Table 1 Description of study plots and tree samples for estimating precision and accuracy of tree-ring-based death dates

\begin{tabular}{|c|c|c|}
\hline & Plots for estimating precision & $\begin{array}{l}\text { LWF plot for estimating } \\
\text { accuracy }\end{array}$ \\
\hline Repeated assessment of crown condition & No & Yes \\
\hline Number of plots & 20 & 1 \\
\hline Total number of sampled trees & 200 & 29 \\
\hline Percentage of trees with $3,2,1$ extracted cores & $94.5,5,0.5 \%$ & $93.1,6.9,0 \%$ \\
\hline Sampling height of core $\mathrm{B}$ (mean \pm standard deviation) $(\mathrm{cm})$ & $36.5 \pm 11.4$ & $30.4 \pm 6.1$ \\
\hline Sampling height of core $\mathrm{L}$ (mean \pm standard deviation) $(\mathrm{cm})$ & $83.3 \pm 22.9$ & $94.1 \pm 19.9$ \\
\hline Sampling height of core $\mathrm{R}$ (mean \pm standard deviation) $(\mathrm{cm})$ & $84.4 \pm 24.7$ & $98.3 \pm 20.8$ \\
\hline DBH (mean \pm standard deviation; maximum) & $17.4 \pm 5.0 \mathrm{~cm}(33.7 \mathrm{~cm})$ & $16.7 \pm 3.7 \mathrm{~cm}(25.3 \mathrm{~cm})$ \\
\hline Tree height (mean \pm standard deviation; minimum, maximum) & $9.4 \pm 2.5 \mathrm{~m}(3.2,16.6 \mathrm{~m})$ & \\
\hline Elevation (mean \pm standard deviation; minimum, maximum) & $2,018 \pm 41 \mathrm{~m}(1,899,2,092 \mathrm{~m})$ & \\
\hline Slope steepness (mean \pm standard deviation; minimum, maximum) & $26.8 \pm 7.6^{\circ}\left(12^{\circ}, 43^{\circ}\right)$ & \\
\hline $\begin{array}{l}\text { Total number of cores, number of measured cores, number } \\
\text { of measured and crossdated cores without eroded outermost tree rings }\end{array}$ & $588,580,513$ & $85,85,79$ \\
\hline Establishment dates (95\% of trees; minimum, maximum) & $1687-1910(1668,1931)$ & \\
\hline Tree-ring-based death dates ( $95 \%$ of trees; minimum, maximum) & 1936-2006 $(1929,2007)$ & \\
\hline Tree ages (95\% of trees; minimum, maximum) & $82-289$ years $(63,333$ years $)$ & \\
\hline
\end{tabular}

Fig. 1 Tree-ring chronology derived from 32 living and 12 dead mountain pines. Only the period from 1695 to 2008 is shown, which is covered by at least five trees. The sample depth represents the number of trees included in the chronology

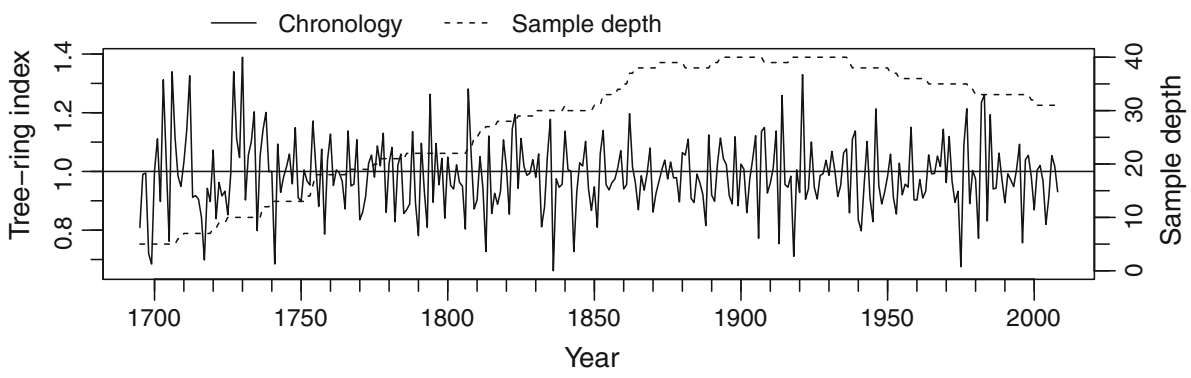

death date was derived from the most recent date of cambial mortality from the three cores, and tree age was estimated based on the establishment date and the tree-ringbased death date.

\section{Data analysis}

To estimate the precision of tree-ring-based death dates (i.e. the within-tree variability of partial cambial mortality) for the dead mountain pines at the 20 plots (Table 1), we calculated the differences of the dates of cambial mortality between cores B and L, between cores B and R, and between cores $\mathrm{L}$ and $\mathrm{R}$. Because the data were not normally distributed, the exact Wilcoxon rank sum test was used to assess whether the dates of cambial mortality differed between the three locations of core sampling. For trees with three measured and crossdated cores, we also calculated the absolute maximum difference between the three dates of cambial mortality (i.e. the difference between the most recent and the oldest date of cambial mortality).
For the dead mountain pines sampled at the 20 plots, effects of site- and tree-specific variables on the absolute maximum difference between the dates of cambial mortality were quantified using generalized linear mixedeffects models (Bolker et al. 2009). The response variable was modelled using a Poisson distribution:

$f\left(y ; \mu_{t p}\right) \sim \operatorname{Poisson}\left(\mu_{t p}\right)$

which is the probability of observing a maximum difference of $y$ years conditional on the expected maximum difference $\mu_{\mathrm{tp}}$ for tree $t$ at plot $p$. A log link function was used to estimate $\mu$ :

$\log \left(\mu_{t p}\right)=a+b X_{t p}+\alpha_{p}+\varepsilon_{t p}$

$\alpha_{p} \sim \operatorname{Normal}\left(0, \sigma_{\text {plot }}^{2}\right)$ and $\varepsilon_{t p} \sim \operatorname{Normal}\left(0, \sigma_{\text {tree }}^{2}\right)$

with intercept $a$, regression coefficient $b$, and predictor variable $X$. The random effect $\alpha$ accounts for the betweenplot variability, $\varepsilon$ is a tree-level random effect accounting for the overdispersion of the data (Zuur et al. 2012). The following site- and tree-specific variables were used to fit the models: aspect of the plot (north, east, south, west), 
Fig. 2 Precision of tree-ringbased death dates estimated for dead mountain pines from 20 plots: a barplots of the differences of cambial mortality between cores $\mathrm{B}$ and $\mathrm{L}(n=95$ trees), between cores $\mathrm{B}$ and $\mathrm{R}$ ( $n=98$ trees), and between cores $\mathrm{L}$ and $\mathrm{R}(n=99$ trees); b barplot of the absolute maximum differences between the three dates of cambial mortality ( $n=83$ trees)
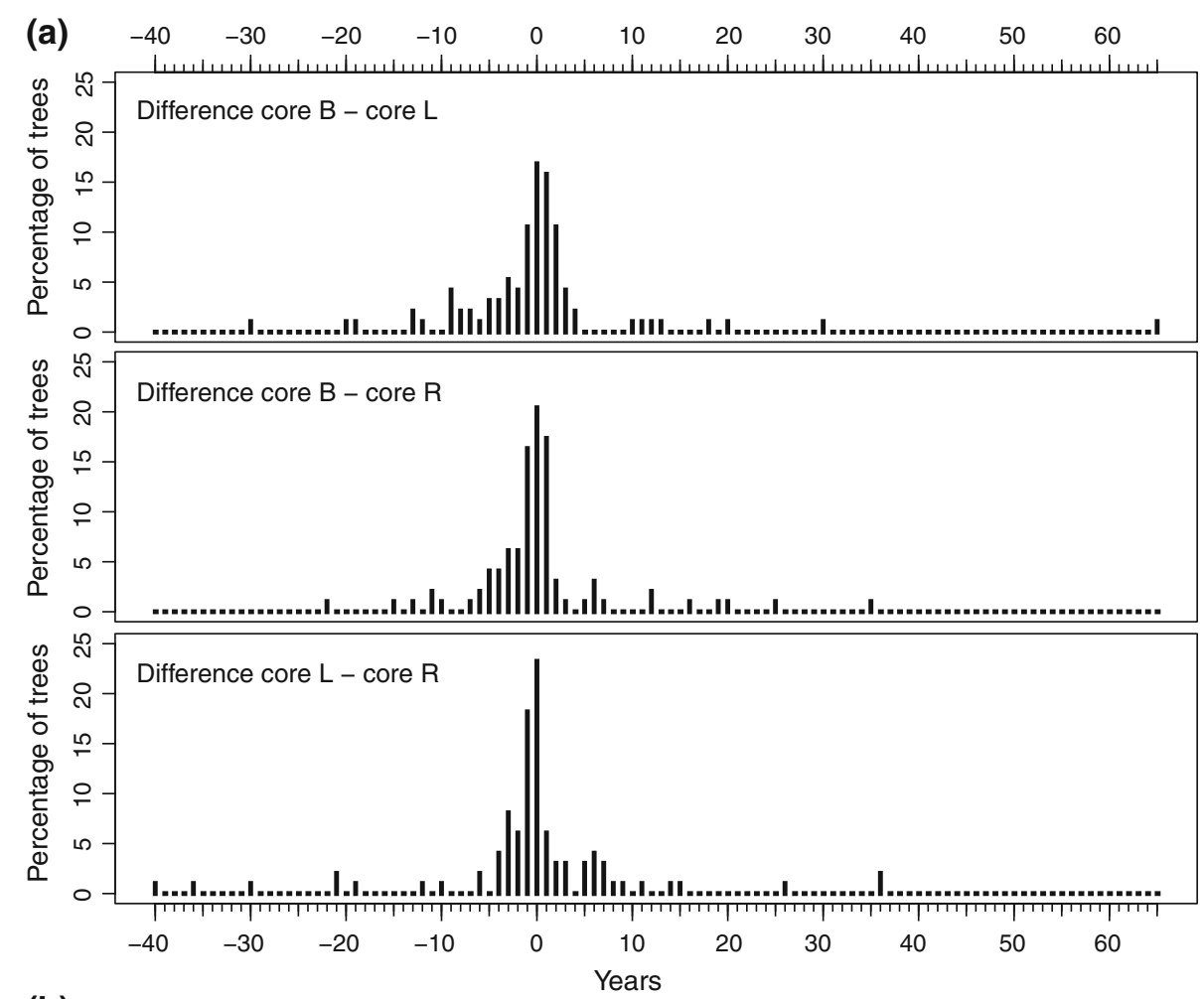

(b)

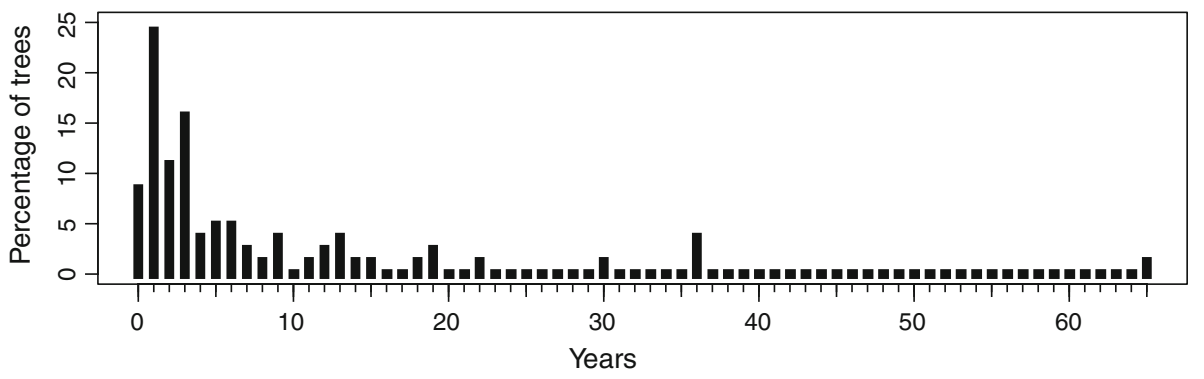

elevation, slope steepness, DBH, tree height, tree decay, bark remaining on the stem, tree age, and tree-ring-based death date. The establishment date was not considered because of the high correlation with tree age (Pearson's correlation $r=-0.91$ ). Because we did not aim for a predictive model but rather for assessing whether any of these predictor variables affected the response variable, we fitted for each variable a separate model.

To estimate the accuracy of tree-ring-based death dates for the dead mountain pines sampled at the LWF plot (Table 1), we calculated the differences between the dates of crown mortality (i.e. the year when a tree reached $100 \%$ crown transparency) and the tree-ring-based death dates. Accuracy was estimated for 19 mountain pines, for which three measured and crossdated cores were available. The relevant temporal resolution of the crown assessments is contingent on the last two assessments for each tree, which was 1 year for $6.9 \%$ of the trees, 2 years for $86.2 \%$ of the trees, and 3 years for $6.9 \%$ of the trees. For example, if the tree-ring-based death date was 2001 and the last two crown assessments for this tree were conducted in 2005 and 2007 (i.e. $100 \%$ crown transparency was observed in 2007, hence, crown mortality occurred either in 2006 or in 2007), the accuracy for this tree was estimated to be 5-6 years.

To quantify the effect of sampling just one or two cores per tree on the accuracy of tree-ring-based death dates, we drew for each tree 1,000 random samples from the three dates of cambial mortality. In the case of sampling two cores, each sample was drawn without replacement and the tree-ring-based death date was determined to be the more recent of the two dates. Accuracy was calculated as the difference between the date of crown mortality and the treering-based death date as in the case of sampling three cores.

The statistical computing software $\mathrm{R}$ (version 2.15.1, R Core Team 2012) was used to conduct the data analyses. To fit the generalized linear mixed-effects models, we applied the "glmer" function in the "Ime4" package (Bates et al. 2012). 
Table 2 Description of generalized linear mixed-effects models for predicting the maximum difference between the dates of cambial mortality

\begin{tabular}{|c|c|c|c|c|}
\hline \multicolumn{2}{|l|}{ Fixed effects ${ }^{\mathrm{a}}$} & \multicolumn{2}{|l|}{ Random effects ${ }^{\mathrm{a}}$} & \multirow[t]{2}{*}{ AIC } \\
\hline Intercept $(a)$ & Variable $(b)$ & Plot-level random effect $\left(\alpha_{\mathrm{p}}\right)$ & Tree-level random effect $\left(\varepsilon_{\mathrm{tp}}\right)$ & \\
\hline $1.25 \pm 0.38(<0.001)$ & $\begin{array}{l}\text { Aspect of the plot: } \\
\text { North }=0.023 \pm 0.521(0.96) \\
\text { South }=-0.240 \pm 0.544(0.66) \\
\text { West }=0.569 \pm 0.553(0.30)\end{array}$ & 0.63 & 0.97 & 241.3 \\
\hline$-1.80 \pm 9.45(0.85)$ & $\begin{array}{l}\text { Elevation: } \\
0.0015 \pm 0.0047(0.74)\end{array}$ & 0.65 & 0.98 & 239.3 \\
\hline$-0.85 \pm 0.57(0.13)$ & $\begin{array}{l}\text { Slope: } \\
0.085 \pm 0.021(<0.0001)\end{array}$ & 0.54 & 0.87 & 224.3 \\
\hline $0.85 \pm 0.53(0.11)$ & $\begin{array}{l}\text { DBH: } \\
0.025 \pm 0.026(0.34)\end{array}$ & 0.66 & 0.98 & 238.5 \\
\hline $0.82 \pm 0.65(0.21)$ & $\begin{array}{l}\text { Tree height: } \\
0.051 \pm 0.062(0.41)\end{array}$ & 0.67 & 0.98 & 238.8 \\
\hline $0.92 \pm 0.47(0.051)$ & $\begin{array}{l}\text { Tree decay: } \\
B=0.40 \pm 0.50(0.42) \\
C=0.57 \pm 0.50(0.26) \\
D=-0.35 \pm 0.79(0.66)\end{array}$ & 0.60 & 0.97 & 240.9 \\
\hline $0.90 \pm 0.36(0.013)$ & $\begin{array}{l}\text { Bark remaining: } \\
0.0077 \pm 0.0052(0.14)\end{array}$ & 0.71 & 0.96 & 237.4 \\
\hline $0.38 \pm 0.50(0.44)$ & $\begin{array}{l}\text { Tree age: } \\
0.0060 \pm 0.0029(0.038)\end{array}$ & 0.62 & 0.95 & 235.4 \\
\hline $35.7 \pm 13.7(0.0092)$ & $\begin{array}{l}\text { Tree-ring-based death date: } \\
-0.0174 \pm 0.0069(0.012)\end{array}$ & 0.44 & 1.01 & 234.4 \\
\hline
\end{tabular}

Models were fitted to 83 trees at 20 plots using a Poisson distribution (Eq. 1) and a log link function (Eq. 2). Estimates \pm standard errors $(P$ values) for the fixed effects and standard errors for the random effects are shown. The AIC (Akaike Information Criterion) is a relative measure of the amount of noise (Stauffer 2008) with lower values indicating better-fitting models. The reference levels for the variable aspect were "east" and decay class "A" for the variable tree decay

a Symbols $\left(a, b, \alpha_{\mathrm{p}}, \varepsilon_{\mathrm{tp}}\right)$ are from Eq. 2

\section{Results}

The precision of tree-ring-based death dates was estimated for the dead mountain pines at the 20 plots (Table 1) by calculating pairwise differences between the dates of cambial mortality from cores $\mathrm{B}, \mathrm{L}$ and $\mathrm{R}$, and by calculating the maximum differences between the dates of cambial mortality from these cores. The distributions of pairwise differences were centred around zero (Fig. 2a) and the medians did not significantly differ from zero (differences between core $\mathrm{B}$ and $\mathrm{L}: P=0.32$, core $\mathrm{B}$ and R: $P=0.17$, core $\mathrm{L}$ and $\mathrm{R}: P=0.61 ; P$ values based on exact Wilcoxon rank sum test). However, the distributions of the differences between core $\mathrm{B}$ and $\mathrm{L}$ and between core $B$ and $R$ were skewed slightly to the left (Fig. 2a), i.e. the formation of the outermost tree rings tended to occur a bit later at the higher sampling height (cores $\mathrm{L}$ and $\mathrm{R}$ ) when compared to the lower sampling height (cores $\mathrm{B}$ ). The absolute difference between cores $\mathrm{L}$ and $\mathrm{R}$ was $0-1$ year for almost $48 \%$ of the trees and $0-4$ years for almost $72 \%$ of the trees (Fig. 2a). Several dates of cambial mortality differed by more than 20 years. The absolute maximum difference based on three cores was $0-1$ year for $33 \%$ of the trees and 0-4 years for $63 \%$ of the trees (Fig. 2b). A few trees $(6 \%)$ had a maximum difference between 30 and 65 years. The absolute maximum differences based on cores $\mathrm{B}, \mathrm{L}$ and $\mathrm{R}$ were highly correlated with the absolute differences between cores L and $\mathrm{R}$ (Pearson's correlation $r=0.93, P<0.0001)$.

Precision as represented by the maximum difference between the dates of cambial mortality was significantly affected by (in decreasing order of importance as indicated by the AIC and $P$ values in Table 2): slope steepness $(P<0.0001)$, tree-ring-based death date $(P=0.012)$ and tree age $(P=0.038)$. Higher maximum differences between the dates of cambial mortality (i.e. lower precision of tree-ring-based death dates) are expected on steep slopes, in trees that died a long time ago and in old trees (Table 2; Fig. 3). These variables were only moderately correlated with other predictor variables (highest Pearson's 

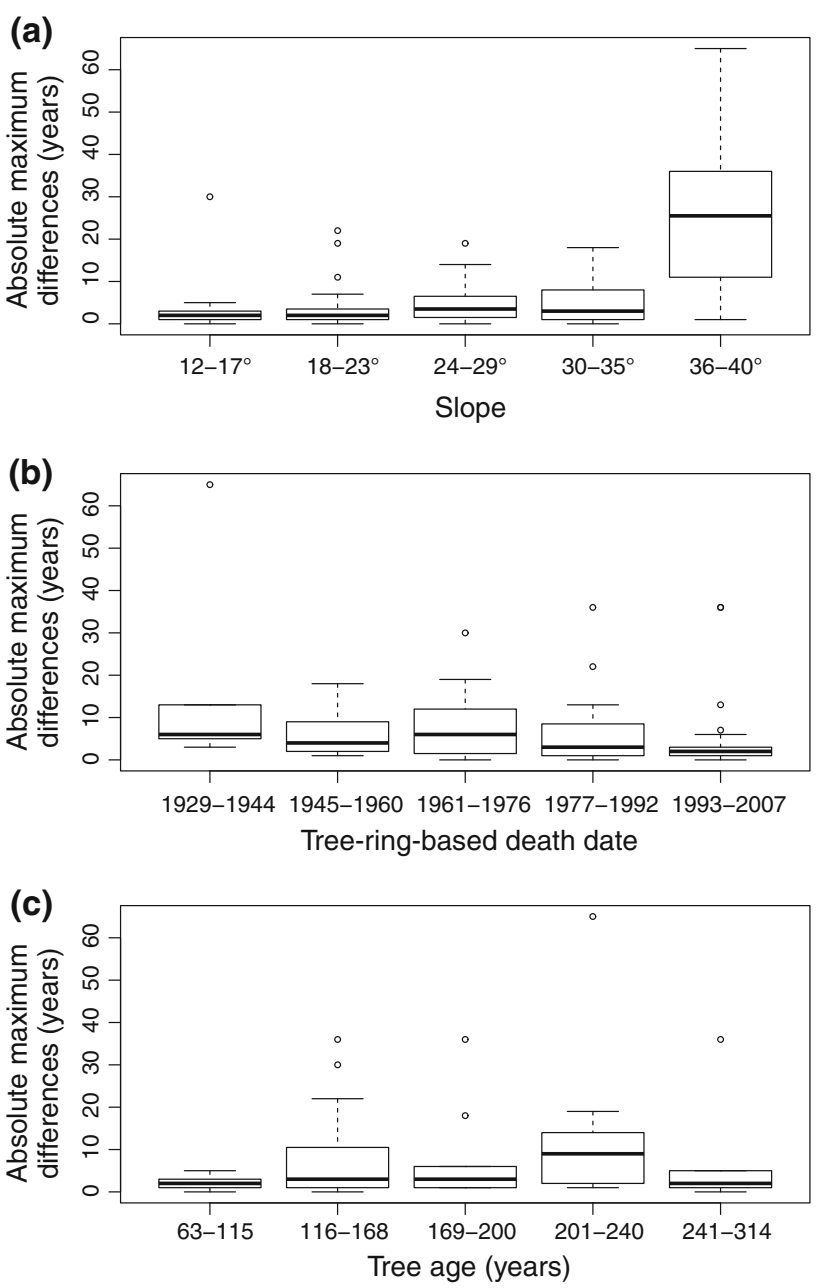

Fig. 3 Relationship between site- and tree-specific variables and precision of tree-ring-based death dates estimated for dead mountain pines ( $n=83$ trees) from 20 plots. Boxplots of the absolute maximum differences between the three dates of cambial mortality and the significant variables are shown (cf. Table 2): a slope; b treering-based death date; $\mathbf{c}$ tree age

correlations: $r=0.24$ for slope and tree age, $r=0.53$ for tree-ring-based death date and bark remaining, $r=0.41$ for tree age and $\mathrm{DBH}$ ), i.e. the significant effects were unlikely to occur due to confounding variables.

The accuracy of tree-ring-based death dates was estimated for the dead mountain pines at the LWF plot (Table 1) as the difference between the date of crown mortality and the tree-ring-based death date. If three cores per tree were considered, the outermost tree ring of $26 \%$ of the trees was formed 1-2 years before reaching $100 \%$ crown transparency (Fig. 4a), $84 \%$ of the trees differed by not more than 5 years between crown mortality and treering-based death date (Fig. 4b). A maximum of 14-15 years was reached by $5 \%$ of the trees (Fig. 4a). Accuracy decreased if just two cores or one core were sampled: based on two cores (one core), $21 \%(12 \%)$ of the trees differed by $1-2$ years and $72 \%(54 \%)$ by (a)

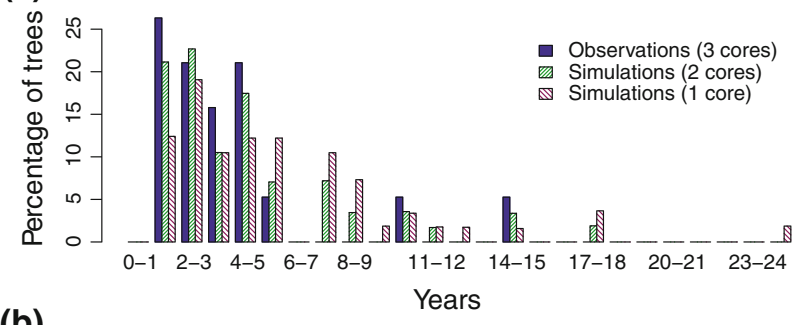

(b)

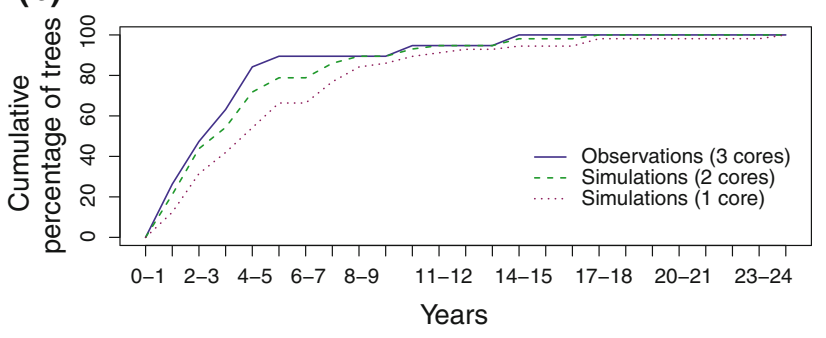

Fig. 4 Accuracy of tree-ring-based death dates estimated for dead mountain pines from the LWF plot. Differences between the dates of crown mortality and the tree-ring-based death dates for observations based on three cores ( $n=19$ trees) and simulations based on 1,000 repetitions of randomly sampling two cores or one core are shown: a percentage of trees; $\mathbf{b}$ cumulative percentage of trees. Because of the 2-year intervals between repeated crown assessments, the differences are indicated in classes $(0-1,1-2,2-3$ years,..$)$

0-5 years (Fig. 4b). Differences to the date of crown mortality increased up to 17-18 years for two cores and up to 24-25 years for one core.

\section{Discussion}

Precision of tree-ring-based death dates

Most dead mountain pines in the Swiss National Park (SNP) showed evidence of partial cambial mortality, which affects the precision of tree-ring-based death dates. However, for a majority of the trees, the precision of tree-ringbased death dates is still relatively high. The dates of cambial mortality did not significantly differ between cores from the same or from different sampling heights, though the outermost tree ring at the lower sampling height tended to be formed slightly before the outermost tree ring at the higher sampling height (Fig. 2a). In a case study on dead Norway spruce (Picea abies) in Davos (Switzerland), the outermost tree rings were dated for four radii from each four cross sections sampled at the base of the trees, at $1.30 \mathrm{~m}$, at the lower end of the crown, and in the middle of the crown (Osterwalder 2007). A decreasing variability between the dates of cambial mortality with increasing tree height was observed, however, there was no consistent pattern regarding the most recent dates of cambial mortality along tree height. 
If three cores per tree are considered in our study, onethird of the trees had a maximum difference of not more than 1 year and almost two-thirds of the trees showed a difference up to 4 years (Fig. 2b). Based on the two cores of the same sampling height (cores L and R; Fig. 2a), $48 \%$ of the trees had a difference of not more than 1 year $(72 \%$ up to 4 years). These values agree with the findings from related studies that have reported differences of 0-1 year (0-4 years) between the dates of cambial mortality from two cores of dead standing, non-stripped trees: $43 \%$ (76\%) for mountain pines on the LWF plot in the SNP (Cherubini et al. 2002); $63 \%(81 \%)$ for white spruce (Picea glauca) and $25 \%$ (61\%) for lodgepole pine (Pinus contorta) in Alberta, Canada (Jones and Daniels 2012); $39 \%(76 \%)$ for yellow-cedar (Chamaecyparis nootkatensis) in British Columbia, Canada (Stan et al. 2011); and $45 \%(75 \%)$ for Engelmann spruce (Picea engelmannii) and $66 \%(90 \%)$ for subalpine fir (Abies lasiocarpa) in Colorado, USA (Bigler et al. 2007). Amoroso and Daniels (2010) estimated for $28 \%$ of living but declining Cordilleran cypress (Austrocedrus chilensis) in Rio Negro (Argentina) a difference of $0-1$ year (almost $50 \%$ up to 4 years) between the date of cambial mortality from one core per tree and the date of sampling.

The maximum difference between two cores of the same sampling height was 40 years in our study (Fig. 2a). In previous studies, the maximum values ranged from 13 years for yellow-cedar (Stan et al. 2011) to 39 years for Cordilleran cypress (Amoroso and Daniels 2010) up to 63 years for lodgepole pine (Jones and Daniels 2012). Thus, sampling just one core per tree may underestimate in a majority of dead or declining trees the formation date of the outermost tree rings by several years up to several decades. These observations from a wide range of tree species and sites reflect that partial cambial mortality is the rule rather than the exception in declining, non-stripped trees.

Site- and tree-specific effects on partial cambial mortality

Partial cambial mortality in declining, non-stripped trees, such as the mountain pines in the SNP, may result from reduced availability of resources, which is a consequence of the allocation pattern in trees. The allocation of carbon and nutrients into stem, roots, foliage, defenses and reproduction results in trade-offs, which are modified by external drivers such as climate extremes, neighbourhood effects or disturbances (Barringer et al. 2013; Franklin et al. 2012; Ogle and Pacala 2009). Because maintaining continuous stem growth is often not essential for the shortterm survival of a tree, stem growth is assigned a relatively low priority in the whole-tree allocation scheme, which is reflected in reduced radial growth rates or missing tree rings in stressed or declining trees (Waring 1987; Dobbertin 2005; Rigling et al. 2002). Partial cambial mortality, particularly the more extreme form of strip-bark growth, has been suggested to be a life-extending measure as has been observed in several conifer species growing in harsh environments (Schulman 1954; Lanner 2002).

Slope steepness seems to be the strongest determinant of partial cambial mortality in our study. The larger expected difference between the dates of cambial mortality in trees growing on steeper slopes (Table 2), particularly on slopes with $>35^{\circ}$ inclination (Fig. 3a), indicates that mechanical forces due to gravity and snow movements play an important role in determining how carbon is allocated along the tree stem. Previous studies on strip-bark trees provided evidence of wind as a cause of partial cambial mortality in Pinus aristata (Schauer et al. 2001) and of rockfall in Thuja occidentalis growing on cliffs (Kelly et al. 1992). The positive correlation between tree age and the maximum difference between the dates of cambium mortality (Table 2; Fig. 3c) in our study probably arises because the maximum difference is necessarily a fraction of tree age. Thus, the more frequent occurrence of strip-bark growth in older trees (LaMarche 1969; Kelly et al. 1992) agrees with the findings from our study on non-stripped mountain pines. Trees that died a long time ago tend to have a larger difference between the dates of cambial mortality (Fig. 3b). This effect is not related to decay of wood, since (i) we avoided stem sections with eroded wood in the field, (ii) cores with eroded tree rings were omitted and (iii) no significant effects for the variables tree decay or bark remaining on the stem were detected (Table 2). For any of the significant variables (slope, tree age, tree-ring-based death date), the effects were unlikely to be confounded by other measured variables.

\section{Accuracy of tree-ring-based death dates}

The tree-ring-based death dates of the dead mountain pines in the SNP were not only influenced by partial cambial mortality, which affects precision, but also by the lagged crown mortality following cambial mortality, which affects accuracy (Fig. 4a). For all cored trees on the permanent sample plot, tree-ring production stopped at least 1 year before $100 \%$ crown transparency was reached. Eighty-four percent of the death dates derived from three cores differed by not more than 5 years from the death dates derived from the crown assessments (Fig. 4b). Thus, the accuracy from tree-ring-based death dates in our study exceeds the accuracy from many permanent sample plots, where intervals between repeated crown assessments typically range between 5 and 15 or even more years (Rigling et al. 2013; Rohner et al. 2012). However, reducing the sampling effort 
in our tree-ring analysis decreases the fraction of trees with a difference between crown-based and tree-ring-based death date of $0-5$ years to $72 \%$ if two cores are sampled or to only $54 \%$ if one core is sampled. Sampling just one or two cores also results in a higher fraction of inaccurate tree-ring-based death dates, i.e. deviations of up to 25 years may be encountered. We suggest that large differences between tree-ring-based death dates and crown mortality should not be interpreted as the ability of trees to survive so many years, but rather reflect a sampling artefact. A more intense sampling of dead trees, e.g. sampling of several stem disks per tree and dating the outermost tree ring along several radii per stem disk (Osterwalder 2007; see also the study by Novak et al. 2011 on missing rings in living Pinus species), will probably yield even a higher accuracy of tree-ring-based death dates than that reached in our study (Fig. 4). However, such a follow-up research project needs to be conducted in permanent sample plots with short intervals between repeated crown assessments.

Relatively few studies provide estimates of accuracy by comparing tree-ring-based death dates with observed death dates, and most of the reported estimates are from nonsystematic samples of trees. Cherubini et al. (2002) sampled dead mountain pines in the LWF plot of the SNP and reported a maximum difference of 31 years. We assume that this large discrepancy is partly due to the sampling scheme, i.e. two cores per tree were removed at different heights but on the same side of the stem (P. Cherubini, personal communication). Pedersen and McCune (2002) found for a sample of eight trees from mixed-species stands that six trees formed the outermost tree ring in the year of tree death, whereas two trees differed by 4 and 8 years, respectively. Mast and Veblen (1994) reported tree-ring production in Engelmann spruce-subalpine fir stands to stop typically 1-3 years before tree death. A systematic assessment of the accuracy of tree-ring-based death dates in permanent sample plots in Alberta (Canada) revealed that the tree-ring-based death dates of $70 \%$ of white spruce snags and of $49 \%$ of lodgepole pine snags were found to be within the remeasurement intervals (Jones and Daniels 2012). However, due to the relatively long remeasurement intervals of 5-34 years, these findings cannot be directly compared with those from our study.

\section{Conclusions}

Many ecological studies dealing with forest dynamics and the reconstruction of mortality rates rely on accurate dates of tree death that are commonly derived from dating the outermost tree ring of dead trees. Our study on dead mountain pines in the Swiss National Park is a contribution towards quantifying two important sources of error: partial cambial mortality affects the precision of tree-ring-based death dates, and the difference between the date of crown mortality and the most recent date of cambial mortality affects the accuracy of tree-ring-based death dates. For many mountain pines the difference due to partial cambial mortality is limited to just a few years, however, for some trees substantial deviations of several decades may be encountered. Our observations further indicate that many mountain pines continue to live for another $1-5$ years after the cessation of wood production. However, this finding is contingent on the selected sampling height, but may not apply to the entire tree. Increasing the sampling effort, i.e. extracting more cores per tree, results in more accurate estimates of the date of tree death. For the mountain pines in the Swiss National Park, we recommend to sample more cores particularly in trees growing on very steep slopes and in old trees. To get an estimate of the accuracy of tree-ringbased death dates, we further suggest to sample dead trees in permanent sample plots with short intervals between repeated crown assessments. If data from permanent sample plots are lacking, dead trees may be sampled that have been observed to die within the last 1-2 years.

Acknowledgments We acknowledge the permit to conduct fieldwork in the Swiss National Park. We would like to thank Veronique Ringwald for providing support in the tree-ring lab and Marco Vanoni for his comments on an earlier version of the manuscript. We would also like to thank the reviewers for commenting on the manuscript. Jochen Breschan provided helpful support with the GPS and the GIS software. This study is dedicated to our friend and colleague Matthias Dobbertin, who passed away unexpectedly. He coordinated the LWF monitoring network for many years, which made this research possible.

\section{References}

Amoroso MM, Daniels LD (2010) Cambial mortality in declining Austrocedrus chilensis forests: implications for stand dynamics studies. Can J For Res 40(5):885-893

Barringer BC, Koenig WD, Knops JMH (2013) Interrelationships among life-history traits in three California oaks. Oecologia 171(1):129-139

Bates D, Mächler M, Bolker B (2012) lme4: Linear mixed-effects models using S4 classes. R package version 0.999999-0. URL http://CRAN.R-project.org/package=lme4

Bigler C, Veblen TT (2009) Increased early growth rates decrease longevities of conifers in subalpine forests. Oikos 118(8): $1130-1138$

Bigler C, Gavin DG, Gunning C, Veblen TT (2007) Drought induces lagged tree mortality in a subalpine forest in the Rocky mountains. Oikos 116(12):1983-1994

Bolker BM, Brooks ME, Clark CJ, Geange SW, Poulsen JR, Stevens MHH, White J-SS (2009) Generalized linear mixed models: a practical guide for ecology and evolution. Trends Ecol Evol 24(3):127-135

Cherubini P, Fontana G, Rigling D, Dobbertin M, Brang P, Innes JL (2002) Tree-life history prior to death: two fungal root pathogens affect tree-ring growth differently. J Ecol 90:839-850 
Daniels LD, Dobry J, Klinka K, Feller MC (1997) Determining year of death of logs and snags of Thuja plicata in southwestern coastal British Columbia. Can J For Res 27(7):1132-1141

Dobbertin M (2005) Tree growth as indicator of tree vitality and of tree reaction to environmental stress: a review. Eur J For Res 124:319-333

Dobbertin M, Baltensweiler A, Rigling D (2001) Tree mortality in an unmanaged mountain pine (Pinus mugo var. uncinata) stand in the Swiss National Park impacted by root rot fungi. For Ecol Manage 145:79-89

Duncan RP (1989) An evaluation of errors in tree age estimates based on increment cores in Kahikatea (Dacrycarpus dacrydioides). NZ Nat Sci 16:31-37

Fischer R, Waldner P, Carnicer J, Coll M, Dobbertin M, Ferretti M, Hansen K, Kindermann G, Lasch-Born P, Lorenz M, Marchetto A, Meining S, Nieminen T, Peñuelas J, Rautio P, Reyer C, Roskams P, Sánchez G (2012) The condition of forests in Europe. 2012 Executive Report. ICP Forests, Hamburg

Franklin O, Johansson J, Dewar RC, Dieckmann U, McMurtrie RE, Brannstrom A, Dybzinski R (2012) Modeling carbon allocation in trees: a search for principles. Tree Physiol 32(6):648-666

Holmes RL (1983) Computer-assisted quality control in tree-ring dating and measuring. Tree-Ring Bull 43:69-78

Jones EL, Daniels LD (2012) Assessment of dendrochronological year-of-death estimates using permanent sample plot data. TreeRing Res 68(1):3-16

Kelly PE, Cook ER, Larson DW (1992) Constrained growth, cambial mortality, and dendrochronology of ancient Thuja occidentalis on cliffs of the Niagara escarpment: an eastern version of the bristlecone pine? Int J Plant Sci 153:117-127

LaMarche VC Jr (1969) Environment in relation to age of bristlecone pines. Ecology 50:53-59

Lanner RM (2002) Why do trees live so long? Ageing Res Rev 1:653-671

Larson DW, Matthes-Sears U, Kelly PE (1993) Cambial dieback and partial shoot mortality in cliff-face Thuja occidentalis: evidence for sectored radial architecture. Int J Plant Sci 154:496-505

Lorenz M (1995) International co-operative programme on assessment and monitoring of air pollution effects on forests - ICP Forests. Water Air Soil Pollut 85:1221-1226

Lotz A (ed) (2006) Alpine habitat diversity-HABITALP—project report 2002-2006. EU Community Initiative INTERREG III B Alpine Space Programme, Nationalpark Berchtesgaden

Mast JN, Veblen TT (1994) A dendrochronological method of studying tree mortality patterns. Phys Geogr 15(6):529-542

Metsaranta JM, Lieffers VJ (2009) Using dendrochronology to obtain annual data for modelling stand development: a supplement to permanent sample plots. Forestry 82(2):163-173

Novak K, de Luis M, Cufar K, Raventos J (2011) Frequency and variability of missing tree rings along the stems of Pinus halepensis and Pinus pinea from a semiarid site in SE Spain. J Arid Environ 75(5):494-498

Ogle K, Pacala SW (2009) A modeling framework for inferring tree growth and allocation from physiological, morphological, and allometric traits. Tree Physiol 29(4):587-605

Osterwalder N (2007) Dendrochronologische Untersuchung des Absterbeprozesses von Fichten in subalpinen Wäldern. Diploma thesis, ETH Zürich
Parolini JD (2012) Vom Kahlschlag zum Naturreservat. Geschichte der Waldnutzung im Gebiet des Schweizerischen Nationalparks. Nationalpark-Forschung in der Schweiz 96. Haupt Verlag, Bern, Stuttgart, Wien

Pedersen BS, McCune B (2002) A non-invasive method for reconstructing the relative mortality rates of trees in mixedage, mixed-species forests. For Ecol Manage 155:303-314

R Core Team (2012) R: a language and environment for statistical computing. R Foundation for Statistical Computing, Vienna, Austria. URL http://www.R-project.org

Richardson DM (ed) (1998) Ecology and biogeography of Pinus. Cambridge University Press, Cambridge

Rigling A, Bräker O, Schneiter G, Schweingruber F (2002) Intraannual tree-ring parameters indicating differences in drought stress of Pinus sylvestris forests within the Erico-Pinion in the Valais (Switzerland). Plant Ecol 163:105-121

Rigling A, Bigler C, Eilmann B, Feldmeyer-Christe E, Gimmi U, Ginzler C, Graf U, Mayer P, Vacchiano G, Weber P, Wohlgemuth T, Zweifel R, Dobbertin M (2013) Driving factors of a vegetation shift from Scots pine to pubescent oak in dry Alpine forests. Glob Chang Biol 19(1):229-240

Rohner B, Bigler C, Wunder J, Brang P, Bugmann H (2012) Fifty years of natural succession in Swiss forest reserves: changes in stand structure and mortality rates of oak and beech. J Veg Sci 23(5):892-905

Rötheli E, Heiri C, Bigler C (2012) Effects of growth rates, tree morphology and site conditions on longevity of Norway spruce in the northern Swiss Alps. Eur J For Res 131(4):1117-1125

Schauer AJ, Schoettle AW, Boyce RL (2001) Partial cambial mortality in high-elevation Pinus aristata (Pinaceae). Am J Bot 88(4):646-652

Schulman E (1954) Longevity under adversity in conifers. Science 119:396-399

Smith JM, Hart SJ, Chapman TB, Veblen TT, Schoennagel T (2012) Dendroecological reconstruction of 1980 s mountain pine beetle outbreak in lodgepole pine forests in northwestern Colorado. Ecoscience 19(2):113-126

Speer JH (2010) Fundamentals of tree-ring research. The University of Arizona Press, Tucson

Stan AB, Maertens TB, Daniels LD, Zeglen S (2011) Reconstructing population dynamics of yellow-cedar in declining stands: baseline information from tree rings. Tree-Ring Res 67(1):13-25

Stauffer HB (2008) Contemporary Bayesian and frequentist statistical research methods for natural resource scientists. Wiley and Sons, Hoboken

Villalba R, Veblen TT (1998) Influences of large-scale climatic variability on episodic tree mortality in northern Patagonia. Ecology 79:2624-2640

Waring RH (1987) Characteristics of trees predisposed to die. Bioscience 37:569-574

Zoller H (1995) Vegetationskarte des Schweizerischen Nationalparks. Erläuterungen. Nationalpark-Forschung in der Schweiz 85:1-108

Zuur AF, Saveliev AA, Ieno EN (2012) Zero inflated models and generalized linear mixed models with R. Highland Statistics Ltd, Newburgh 